\title{
Hypothalamic growth hormone secretagogue receptor regulates growth hormone secretion, feeding, and adiposity
}

\author{
Yujin Shuto, ${ }^{1}$ Tamotsu Shibasaki, ${ }^{2}$ Asuka Otagiri, ${ }^{2}$ Hideki Kuriyama, ${ }^{2}$ Hisayuki Ohata, ${ }^{2}$ \\ Hideki Tamura, ${ }^{1}$ Jun Kamegai, ${ }^{1}$ Hitoshi Sugihara, ${ }^{1}$ Shinichi Oikawa, ${ }^{1}$ \\ and Ichiji Wakabayashi ${ }^{1}$
}

${ }^{1}$ Department of Medicine, and

${ }^{2}$ Department of Physiology, Nippon Medical School, Tokyo, Japan

Address correspondence to: Yujin Shuto, Department of Medicine, Nippon Medical School, 1-1-5 Sendagi, Bunkyo-ku, Tokyo 113-8603, Japan. Phone: 81-3-3822-2131; Fax: 81-3-5811-5795; E-mail: shuto@nms.ac.jp.

Received for publication May 17, 2001, and accepted in revised form April 17, 2002.

Growth hormone secretagogues (GHSs) stimulate GH secretion and food intake. GHS receptor (GHS-R) mRNA has been identified mainly in the arcuate nucleus (Arc) and ventromedial nucleus of the hypothalamus and in the pituitary. Ghrelin, an endogenous ligand for GHS-R, has recently been purified from rat stomach. Although ghrelin is also expressed in the hypothalamus, the physiological significance of the ghrelin/GHS-R system is still unknown. We have created transgenic (Tg) rats expressing an antisense GHS-R mRNA under the control of the promoter for tyrosine hydroxylase (TH), thus selectively attenuating GHS-R protein expression in the Arc. Tg rats had lower body weight and less adipose tissue than did control rats. Daily food intake was reduced, and the stimulatory effect of GHS treatment on feeding was abolished in Tg rats. GH secretion and plasma insulin-like growth factor-I levels were reduced in female Tg rats. These results suggest that GHS-R in the Arc is involved in the regulation of $\mathrm{GH}$ secretion, food intake, and adiposity.

J. Clin. Invest. 109:1429-1436 (2002). doi:10.1172/JCI200213300.

\section{Introduction}

Growth hormone secretagogues (GHSs), which were developed from met-enkephalin based on conformational energy calculations, peptide chemistry, and biological activity, stimulate GH secretion via a specific receptor (1). An intracerebroventricular (ICV) injection of GHS also stimulates food intake in freely feeding rats (2). The GHS receptor (GHS-R) was cloned and found to be a member of the $G$ protein-coupled receptor superfamily (3). The expression of GHS-R mRNA is observed by in situ hybridization or an RNase protection assay mainly in the arcuate nucleus (Arc) and ventromedial nucleus of the hypothalamus and in the pituitary (4). Ghrelin, an endogenous ligand for GHS-R, has recently been isolated from stomach extracts of rats and subsequently cloned in rats and humans (5). Ghrelin-producing cells are found in the hypothalamus as well as in the stomach (5). As expected, ICV administration of ghrelin stimulated $\mathrm{GH}$ secretion and food intake in rats $(6,7)$. Daily peripheral administration of ghrelin caused weight gain by reducing fat utilization in mice and rats (8). However, the physiological role of endogenous ghrelin in the hypothalamus is still unknown.

To attenuate GHS-R expression in vivo, we attempted to create transgenic ( $\mathrm{Tg}$ ) rats with impaired GHS-R function in the hypothalamus, especially in the Arc. For this purpose, we used a construct that expresses GHS$\mathrm{R}$-specific antisense RNA under the control of the promoter for tyrosine hydroxylase (TH). TH is the rate-lim- iting enzyme in catecholamine biosynthesis and is a marker for the dopaminergic neurons in the hypothalamus. TH-like immunoreactivity is present in most neurons in the ventral part of the Arc that contain GH-releasing hormone (GHRH) (9). GHS-R mRNA hybridizing cells show an extensive overlap with GHRH-expressing neurons (10). These results suggest that a certain number of GHS-R-expressing neurons in the Arc also contain TH. Tg mice bearing a fusion gene containing the $\mathrm{TH}$ promoter and the coding region of the human GH gene have been generated, and these $\mathrm{Tg}$ mice showed human GH-like immunoreactivity in all the catecholaminergic neurons in the hypothalamus (11). Based on this report, an antisense GHS-R mRNA under the control of the TH promoter would be expected to suppress GHS-R expression in the Arc. Therefore, in the present study we have generated $\mathrm{Tg}$ rats that express an antisense GHS-R mRNA under the control of the TH promoter to determine the physiological role of the ghrelin/GHS-R system in the hypothalamus.

\section{Methods}

Generation of $\mathrm{Tg}$ rats. To construct the antisense GHS-R fusion gene, a synthetic 108-nucleotide DNA fragment spanning the $5^{\prime}$ extracellular region of GHS-R was cloned in the antisense orientation into the vector 4.5THpAL+ (kindly provided by Dona Chikaraishi), which contains $4.5 \mathrm{~kb}$ of the upstream region of the rat TH gene (11). The antisense orientation of the cloned fragments was verified by DNA sequencing. A $4.8-\mathrm{kb}$ 


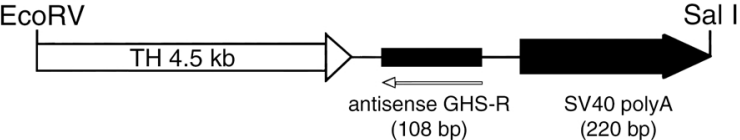

b

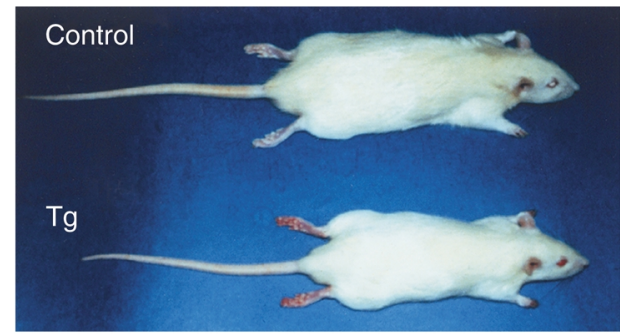

C

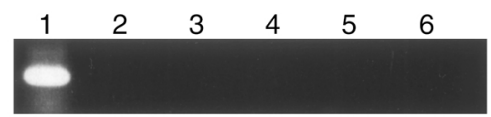

Figure 1

Generation of $\mathrm{Tg}$ rats expressing an antisense GHS-R gene. (a) Schematic structure of the antisense GHS-R transgene. (b) Gross appearance of a 6-week-old $\mathrm{Tg}$ rat and its non-Tg littermate. (c) Expression of the antisense GHS-R gene in Tg rats. Lane 1, hypothalamus; lane 2, heart; lane 3 , liver; lane 4, kidney; lane 5, testis; lane 6, pituitary.

EcoRV-SalI fragment was then microinjected into fertilized eggs of slc:SD rats. Insertion of the DNA was confirmed by PCR analysis of tail DNA. In the experiments described below, the wild-type (slc:SD) inbred strain was used as the control group. All experiments were approved by the Animal Research Committee of Nippon Medical School.

RNA isolation and analysis. Total RNA was extracted from tissues of $\mathrm{Tg}$ rats, and GHS-R antisense mRNA was detected using RT-PCR. cDNA was obtained from $1 \mu \mathrm{g}$ of total RNA using avian myeloblastosis virus reverse transcriptase (Takara Biomedicals, Tokyo, Japan). The synthesized cDNA was amplified by PCR with sense primer $5^{\prime}$-CTGCAGGAATTCCAGCGGCA-3' and antisense primer $5^{\prime}$-TTTAAGGGCACGGGCTGCAG$3^{\prime}$. PCR amplification involved an initial period of denaturation at $94^{\circ} \mathrm{C}$ for 3 minutes followed by 30 cycles consisting of 1 minute of denaturation at $94^{\circ} \mathrm{C}, 1$ minute of annealing at $62^{\circ} \mathrm{C}$, and 1 minute of extension at $72^{\circ} \mathrm{C}$. The PCR products were separated on a $2 \%$ agarose gel, and the bands were visualized with ethidium bromide staining.

In situ bybridization. To make an RNA probe for $\mathrm{TH}$, a 475-bp fragment (nucleotides 789-1263) of the rat TH gene was amplified by RT-PCR, subcloned into PGEMT Easy Vector (Promega Corp., Madison, Wisconsin, USA), and labeled with Biotin RNA Labeling Mix (Roche Diagnostics GmbH, Mannheim, Germany). For a GHS-R antisense probe, a synthetic 108-nucleotide DNA fragment of the GHS-R gene was also subcloned into pGEM-T Easy Vector and labeled using the DIG RNA Labeling Kit (Roche Diagnostics GmbH). Rats were perfused with paraformaldehyde, and brain was removed and kept in fixative containing $20 \%$ sucrose. Frozen $8-\mu \mathrm{m}$ sections of brain were cut. Hybridization was performed at $42^{\circ} \mathrm{C}$ for 12 hours, and then slides were washed. Hybridized TH probes were detected using the TSA Biotin System (NEN Life Science Products Inc., Boston, Massachusetts, USA) and NBT/BCIP solution (Roche Diagnostics GmbH). Hybridized GHS-R antisense probes were also detected with the TMB substrate kit (Vector Laboratories, Burlingame, California, USA).

Western blot analysis. Hypothalamic nuclei of $\mathrm{Tg}$ and control rats were isolated as described by Palkovits (12). Tissues were lysed in RIPA buffer $(50 \mathrm{mM}$ Tris- $\mathrm{HCl}$ at $\mathrm{pH} 8.0,0.1 \%$ sodium dodecyl sulfate, $1 \%$ Nonidet P- 40 , $150 \mathrm{mM} \mathrm{NaCl}$, and $0.5 \%$ deoxycholic acid) containing $1 \mathrm{mM}$ phenylmethylsulfonyl fluoride (Sigma Aldrich, St. Louis, Missouri, USA), then homogenized with a glass homogenizer and centrifuged at $15,000 \mathrm{~g}$ for 15 minutes. The protein concentrations of the supernatants were determined with the DC protein assay (Bio-Rad Laboratories Inc., Hercules, California, USA). Equal amounts of each sample were separated by electrophoresis through $10 \%$ sodium dodecyl sulfate-polyacrylamide gels as described previously (13). Gels were then blotted onto nitrocellulose membranes (Amersham Pharmacia Biotech, Piscataway, New Jersey, USA). The membranes were incubated overnight at $4^{\circ} \mathrm{C}$ with the antibody against GHS-R (1:1,000 dilution) (13). Immunocomplexes were visualized with the ECL Western blotting analysis system (Amersham Pharmacia Biotech). As an internal control, the levels of $\beta$-tubulin
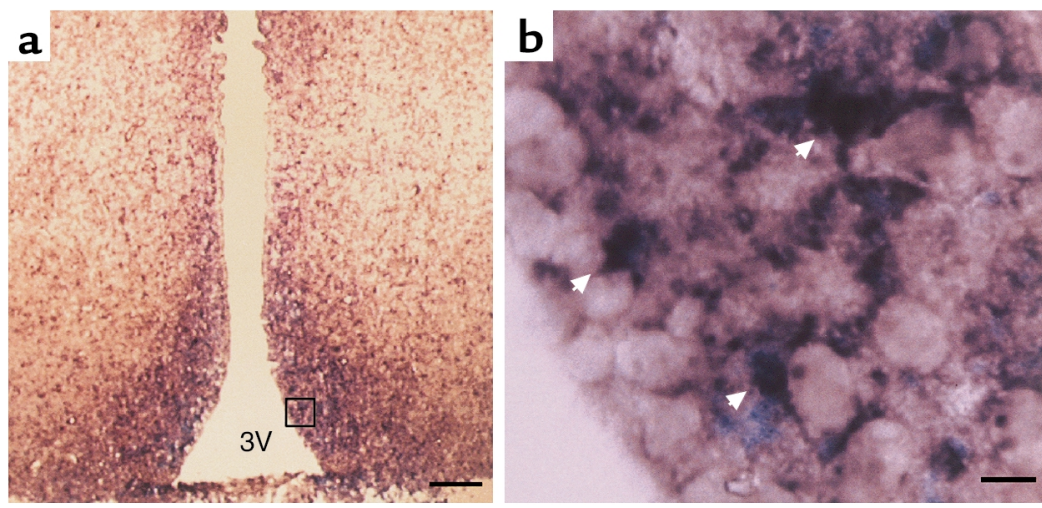

\section{Figure 2}

In situ hybridization of GHS-R antisense mRNA and TH mRNA in the Arc of Tg rats. (a) Low magnification (scale bar: $60 \mu \mathrm{m}$ ). (b) High magnification (scale bar: $6 \mu \mathrm{m}$ ). Almost all the TH neurons (purple) express GHS-R antisense mRNA (blue). Cells with double staining are indicated by arrows. $3 \mathrm{~V}$, third ventricle. 

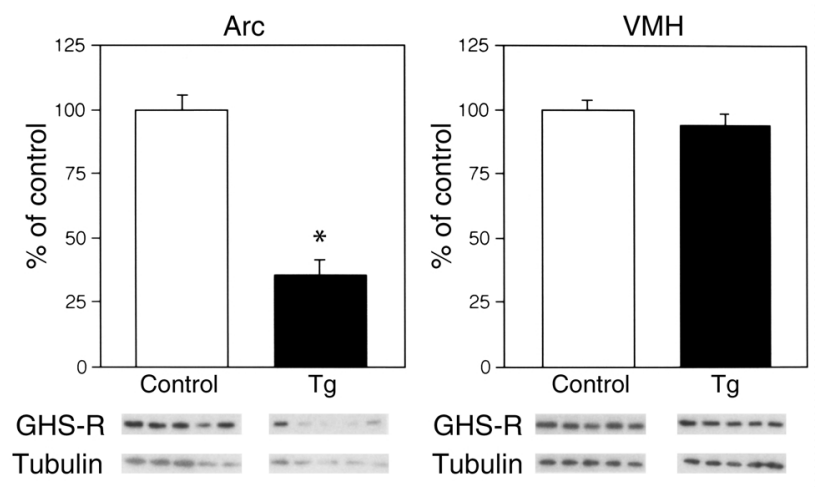

Figure 3

Western blot analysis of GHS-R protein in the hypothalamic nuclei of $\mathrm{Tg}$ rats. The levels of GHS-R protein were corrected for $\beta$-tubulin levels. Data is presented as mean \pm SE for five 8 -week-old rats. ${ }^{*} P<0.05$ versus control rats. $\mathrm{VMH}$, ventromedial nucleus of the hypothalamus.

were also examined using the anti-rat $\beta$-tubulin monoclonal antibody (clone TUB 2.1; ICN Biomedicals Inc., Aurora, Ohio, USA).

Immunocytochemistry. Rats were anesthetized with pentobarbital and perfused via an intracardiac cannula with PBS followed by $4 \%$ paraformaldehyde. The brain was removed, left overnight in $4 \%$ paraformaldehyde, and then transferred to $20 \%$ sucrose/PBS. Sections $(30 \mu \mathrm{m})$ were cut with a sledge microtome and mounted onto gelatinized slides. Immunocytochemistry was performed using the antibody against GHS-R as previously described (13). Briefly, sections were incubated in the primary antiserum (1:100 dilution) for 48 hours at room temperature. Immunostaining was done using the avidin-biotin complex method (Vectastain ABC Elite kit; Vector Laboratories). The reaction product was visualized using a nickel-intensified 3,3'-diaminobenzidine reaction (Sigma Aldrich). Immunocytochemistry for $\mathrm{TH}$ was performed using an anti-TH polyclonal antibody (1:100,000 dilution; Chemicon International, Temecula, California, USA) and visualized using the VIP substrate kit (Vector Laboratories). For double-staining immunocytochemistry, $20-\mu \mathrm{m}$ sections were processed for immunocytochemical detection of GHS-R using the VIP substrate kit (Vector Laboratories). Every third section was incubated with either an anti-GHRH antibody (14) (1:5,000 dilution) or anti-neuropeptide Y (NPY) antibody (15) (1:5,000 dilution) for 24 hours at room temperature. Immunostaining was visualized using the Vector SG substrate kit (Vector Laboratories).

Animal preparations and general protocol. Tg and control rats were housed in air-conditioned animal quarters, with the lights on between 0800 hours and 2000 hours, and were given rat lab chow and water ad libitum. Rats (8 weeks old) were anesthetized with pentobarbital (50 $\mathrm{mg} / \mathrm{kg}$ intraperitoneally), and a catheter was inserted into the right jugular vein.

Five $\mathrm{Tg}$ and five control rats were randomly injected intravenously with KP-102, a GHS that is also known as GHRP-2 $(1 \mu \mathrm{g} / \mathrm{kg}$; Kaken Pharmaceutical Co.,
Tokyo, Japan). Blood samples were collected at $0,5,10$, 15,30 , and 60 minutes after injection. At the end of the experiment, plasma aliquots were assayed for rat $\mathrm{GH}$ with a radioimmunoassay.

To study the GH secretory pattern, rats were anesthetized and provided with an indwelling right atrial cannula 5 days prior to the study. Serial blood specimens $(20 \mu \mathrm{l})$ were withdrawn via the cannula every 10 minutes with an automatic blood sampling device described by Clark and colleagues (16). Blood was collected from 0800 hours to 1600 hours. Each blood specimen was automatically diluted with heparinized saline $(1: 5)$ and assayed directly for rat GH. For the experiments on food intake, rats (6 weeks old) were anesthetized with pentobarbital, and a polyethylene guide cannula was implanted into the right lateral ventricle as previously described $(17,18)$. Five days after the operation, the animals were placed individually in metabolic cages and allowed free access to rat lab chow and water. All experiments were conducted between 1300 hours and 1500 hours. KP-102 or saline was administered intracerebroventricularly in a volume of $2 \mu$ lover 3 minutes, and food intake during the following 2 hours was measured. Daily food consumption was measured from weaning to 12 weeks of age in a cage $(30 \mathrm{~cm} \times 30 \mathrm{~cm}, 38$ $\mathrm{cm}$ in height) equipped with a complete automatic feeding system (PAW 2000; Toyo Industry Co., Tokyo, Japan) connected to a computer.

Hormone assays. Blood was obtained by decapitation early in the morning. GH levels were measured with a radioimmunoassay using materials supplied by NIDDK. Prolactin levels were measured with a rat prolactin assay system (Amersham Pharmacia Biotech). Insulin-like growth factor-I (IGF-I) levels were determined with a radioimmunoassay kit (Diagnostic Systems Laboratories Inc., Webster, Texas, USA) after extraction. Plasma ghrelin concentrations were measured using a ghrelin

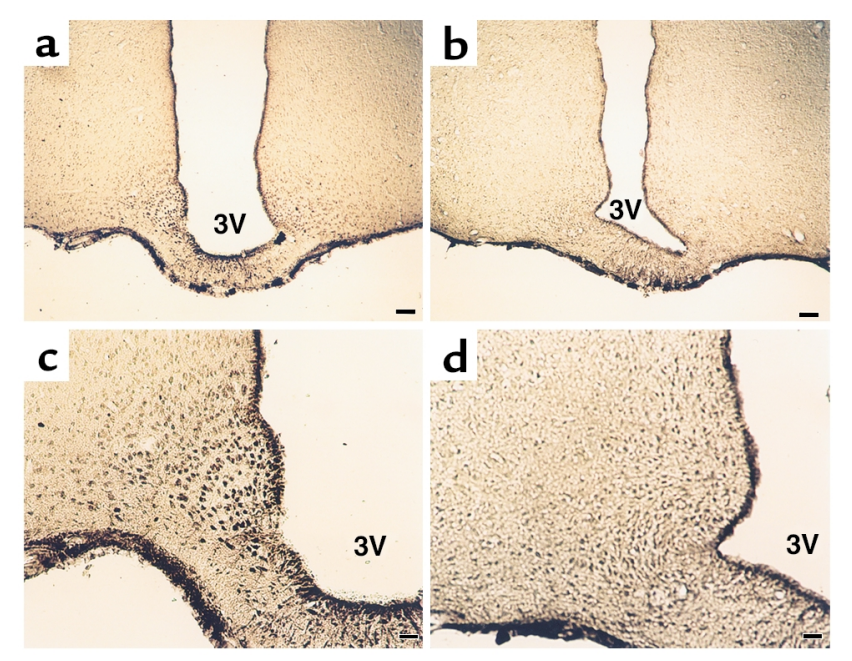

Figure 4

Immunocytochemistry of GHS-R protein in the Arc of control (a and c) and $\mathrm{Tg}$ (b and $\mathbf{d}$ ) rats. (a and $\mathbf{b}$ ) Low magnification (scale bar: 60 $\mu \mathrm{m})$. (c and d) High magnification (scale bar: $24 \mu \mathrm{m}$ ). 

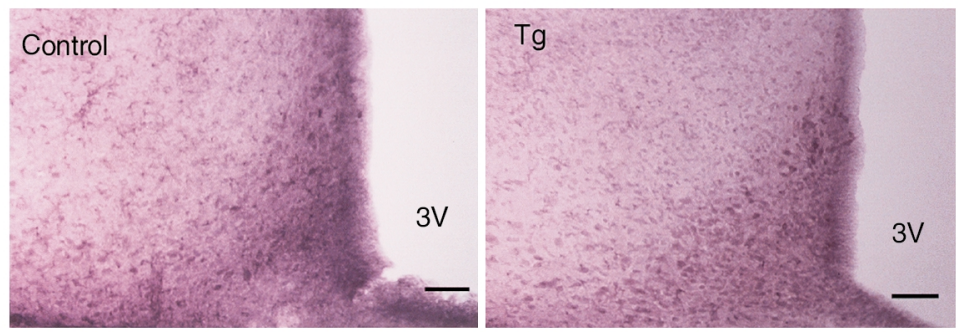

\section{Figure 5}

Immunocytochemistry for TH in control and Tg rats. Scale bars: $40 \mu \mathrm{m}$.
EIA kit (Phoenix Pharmaceuticals Inc., Belmont, California, USA) after extraction with Sep-Pak Plus C18 (Waters Corp., Milford, Massachusetts, USA).

Statistical analysis. All values were expressed as mean \pm SEM. Statistical analysis was performed with ANOVA followed by the Fisher least significant difference test.

\section{Results}

Generation of $\mathrm{Tg}$ rats. We developed $\mathrm{Tg}$ rats that express an antisense RNA for the GHS-R gene under the control of the TH promoter and have reduced levels of GHS-R protein (Figure 1a). The antisense construct was designed to be specific for the region around the initiation codon of GHS-R. Transcription of the antisense sequence was driven by the TH promoter, which usually exhibits activity in GHRH-containing neurons in the $\operatorname{Arc}(9,19,20)$. Fourteen $\mathrm{Tg}$ founder rats were identified using PCR analysis and then crossed with wild-type slc:SD rats. RT-PCR analysis of the hypothalamus showed higher expression of the antisense mRNA in two lines (termed 3-4 and 9-4) than in the other lines, and these two lines were selected to generate homozygous rats. Hemizygous $\mathrm{Tg}$ rats of the two lines were the same size, but were significantly smaller than the non$\mathrm{Tg}$ control rats. Since homozygous rats of the 9-4 line were successfully established first, the 9-4 line was used for the analysis. The homozygous $\mathrm{Tg}$ rats were smaller and leaner than the control rats (Figure 1b). Expression of the antisense mRNA was detected in the hypothala- mus using RT-PCR, whereas there was no detectable antisense mRNA in the heart, liver, kidney, testis, and pituitary of Tg rats (Figure 1c). To examine whether the antisense mRNA is in fact in the TH neurons in the hypothalamus of $\mathrm{Tg}$ rats, double-label in situ hybridization was performed. The antisense mRNA was detected in all the catecholaminergic neurons, whereas no ectopic expression was observed in any brain region of the Tg rats (data not shown). In the Arc, almost all the $\mathrm{TH}$ neurons had the antisense mRNA (Figure 2). There was no detectable antisense mRNA in the hypothalamus of control rats (data not shown). We compared GHS-R protein levels in the Arc and ventromedial nucleus of the $\mathrm{Tg}$ rats with those in the same nuclei of control rats using Western blot analysis. A decrease in the levels of GHS-R protein was seen in the Arc of the $\mathrm{Tg}$ rats, whereas there was no significant difference between $\mathrm{Tg}$ and control rats in the levels of GHS-R protein in the ventromedial nucleus (Figure 3 ).

Immunocytochemistry. Immunocytochemistry for GHS-R demonstrated that the number of GHS-R-positive neurons was remarkably decreased in the Arc of Tg rats compared with control rats (Figure 4). GHS-R-like immunoreactivity was completely eliminated by addition of the synthetic GHS-R fragment (amino acid residues 248-260) used to raise the antiserum (data not shown) (13). The distribution of $\mathrm{TH}$-immunoreactive cell bodies and fibers was similar between $\mathrm{Tg}$ and control rats (Figure 5).
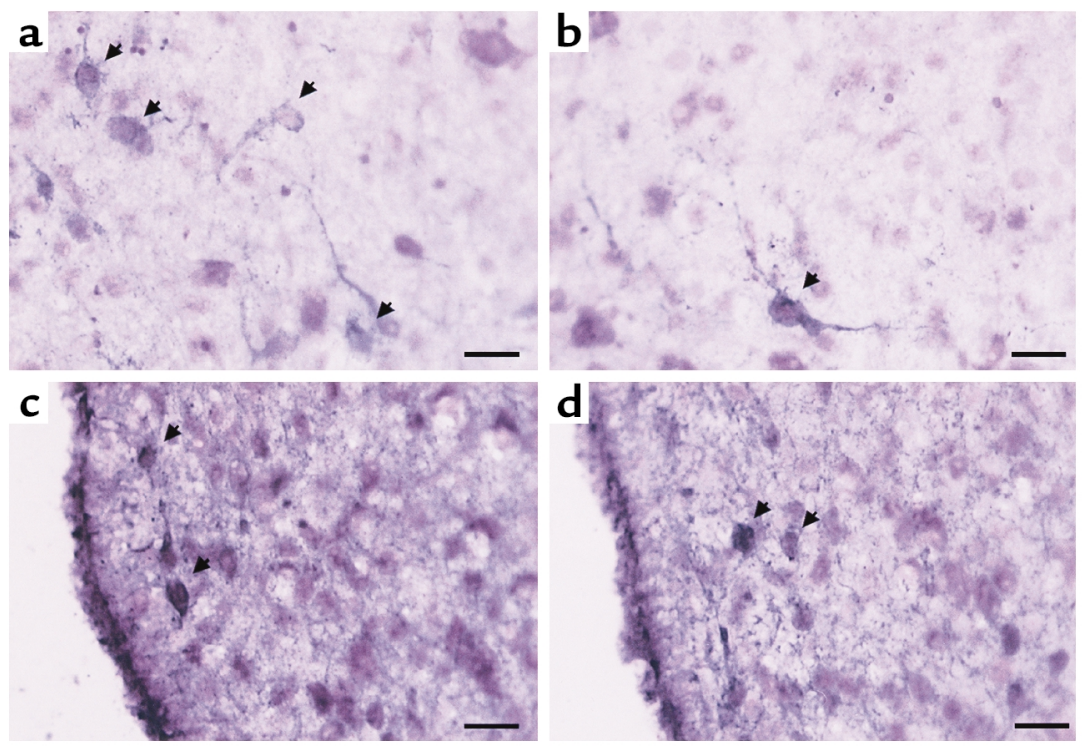

\section{Figure 6}

Double-labeling immunocytochemistry for GHS-R and either GHRH ( $\mathbf{a}$ and $\mathbf{b}$ ) or NPY (c and $\mathbf{d}$ ). (a and $\mathbf{b}$ ) Double-labeling immunocytochemistry for GHS-R (purple staining) and $\mathrm{GHRH}$ (gray staining) in control (a) and $\mathrm{Tg}(\mathbf{b})$ rats. Cells with double staining are indicated by arrows. (c and $\mathbf{d}$ ) Double-labeling immunocytochemistry for GHS-R (purple staining) and NPY (gray staining) in control (c) and Tg (d) rats. Cells with double staining are indicated by arrows. Scale bars: $10 \mu \mathrm{m}$. 

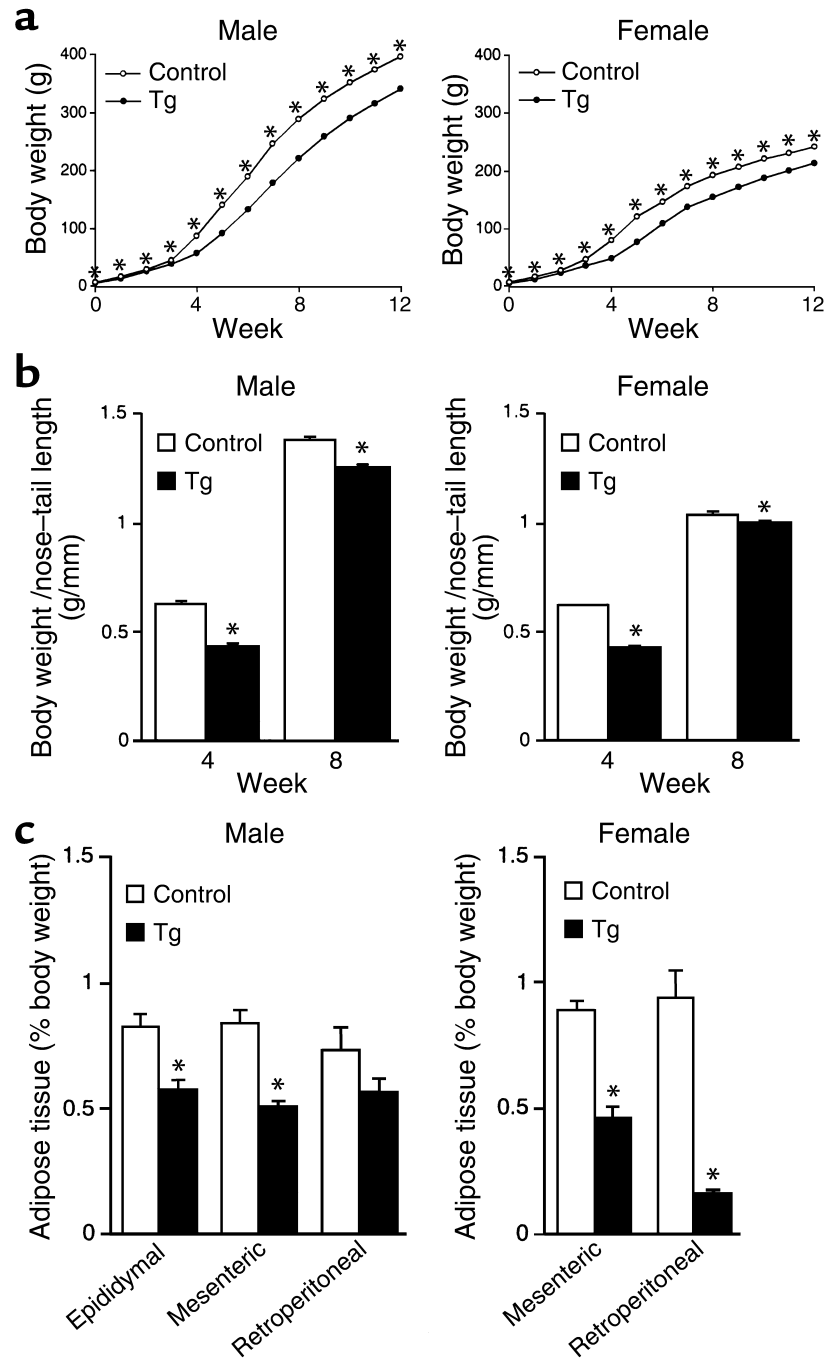

Double-labeling immunocytochemistry showed that many GHRH-immunoreactive neurons in the Arc of control rats contained GHS-R-like immunoreactivity, whereas there were only a few GHRH-immunoreactive neurons that also had GHS-R-like immunoreactivity in Tg rats (Figure 6, a and b). Some, but not all, NPY-immunoreactive neurons in the Arc of both control and $\mathrm{Tg}$ rats contained GHS-R-like immunoreactivity (Figure 6, c and d). There were several NPY-immunoreactive neurons in the Arc of both control and $\mathrm{Tg}$ rats that seemed to lack GHS-R-like immunoreactivity.

Body weight and body fat of $\mathrm{Tg}$ rats. Tg rats were significantly smaller at birth, and a significant difference in body weight between $\mathrm{Tg}$ and control rats was continuously observed throughout the first 12 weeks after birth (Figure $7 \mathrm{a}$ ). Tg rats had lower body weight/nose-tail length ratios, indicating that $\mathrm{Tg}$ rats were lean compared with control rats (Figure $7 \mathrm{~b}$ ). Tg rats had less adipose tissue than did control rats (Figure $7 \mathrm{c}$ ). In male rats, significant differences in epididymal and mesenteric fat as percentage of body weight were

\section{Figure 7}

Characterization of Tg rats. (a) Body weight curves. Each data point represents mean \pm SEM of 8-25 rats (the error bars are smaller than the symbols for many of the data points). ${ }^{*} P<0.05$ versus control rats. (b) Body weight/nose-tail length ratios at 4 and 8 weeks of age. Data are presented as mean \pm SEM of six rats. ${ }^{*} P<0.05$ versus control rats. (c) Adipose tissue (epididymal, mesenteric, and retroperitoneal) weight as a percentage of body weight of 8-week-old Tg rats. Columns represent the mean \pm SEM of six rats. ${ }^{*} P<0.05$ versus control rats.

found between the two groups (Figure 7c). Also, the percentages of mesenteric and retroperitoneal fat tissues were significantly decreased in $\mathrm{Tg}$ female rats compared with those in the control female rats (Figure 7c).

GH secretory pattern and plasma IGF-I, ghrelin, and prolactin concentrations in $\mathrm{Tg}$ rats. To identify GH pulses and baseline levels, data obtained from each rat were analyzed with the PULSAR computer program developed by Merriam and Wachter (21). The usual high bursts of pulsatile GH secretion were observed in male $\mathrm{Tg}$ rats (Figure 8), and there was no significant difference in pulse frequency and baseline concentrations between Tg and control male rats. On the other hand, while the blood GH concentrations of control female rats showed irregular small fluctuations and high baseline levels, $\mathrm{Tg}$ female rats showed low baseline concentrations and few pulses (Figure 8). Baseline GH concentrations in female Tg rats $(9.3 \pm 0.69 \mathrm{ng} / \mathrm{ml})$ were significantly reduced compared with those in control female rats $(23.5 \pm 2.4 \mathrm{ng} / \mathrm{ml}, P<0.05)$, and also, pulse frequency measured over a period of 8 hours was significantly decreased in female $\mathrm{Tg}$ rats $(2.7 \pm 0.25)$ compared with the control female rats $(8.0 \pm 0.1, P<0.05)$. The plasma IGF-I levels were significantly lower in female $\mathrm{Tg}$ rats than in control female rats, whereas there was no significant difference in plasma IGF-I levels between $\mathrm{Tg}$ and control male rats (Figure 9). Plasma ghrelin levels were similar between $\mathrm{Tg}$ and control male rats $(\mathrm{Tg}, 350 \pm 74 \mathrm{pg} / \mathrm{ml}$; control, $198 \pm 32 \mathrm{pg} / \mathrm{ml})$. Also, there was no significant difference in plasma prolactin
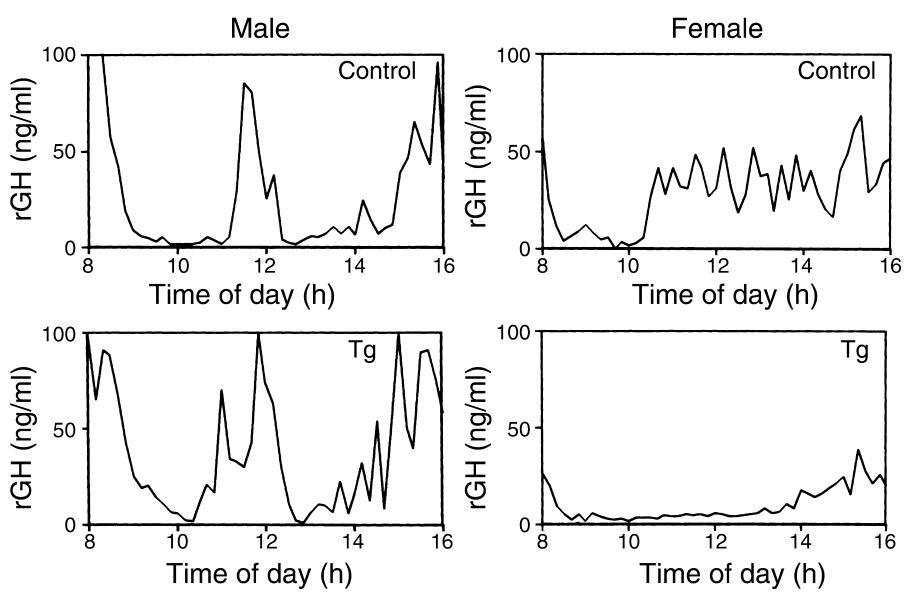

Figure 8

Representative blood $\mathrm{GH}$ profiles of $\mathrm{Tg}$ and control rats. $\mathrm{rGH}$, rat $\mathrm{GH}$. 

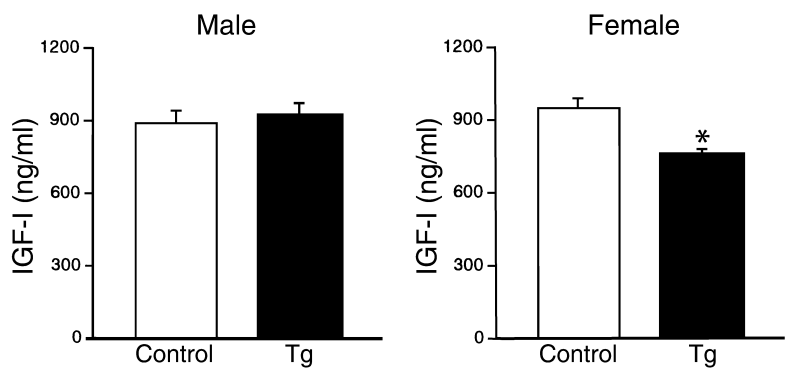

Figure 9

Plasma IGF-I concentrations in Tg rats. Data are presented as mean \pm SEM of six rats. ${ }^{*} P<0.05$ versus control rats.

levels between $\mathrm{Tg}$ and control male rats $(\mathrm{Tg}, 3.6 \pm 1.9$ $\mathrm{ng} / \mathrm{ml}$; control, $7.4 \pm 1.6 \mathrm{ng} / \mathrm{ml})$.

Effect of a GHS on GH release in Tg rats. In both male and female rats, the response of GH to KP-102 in Tg rats was significantly lower than that in control rats (Figure 10). The area under the GH curve was significantly smaller in $\mathrm{Tg}$ rats than in control rats (data not shown). Food intake in Tg rats. Male $\mathrm{Tg}$ rats ate less than agematched control male rats ate from weaning to 8 weeks of age (Figure 11a). Similarly, the food consumption of female $\mathrm{Tg}$ rats was less than that of agematched control female rats at 3, 4, 5, 6, 8, and 9 weeks of age (Figure 11a). As previously reported by our group, ICV injection of KP-102 significantly and dosedependently increased food intake in normal control rats $(2,17,18)$, whereas the effect of KP-102 on food intake was completely abolished in $\mathrm{Tg}$ rats (Figure 11b); even the highest dose of KP-102 (300 ng) did not increase food intake in $\mathrm{Tg}$ rats.

\section{Discussion}

The ability to delete a gene of interest in a tissue-specific manner is a considerable advantage in studying the function of the gene. There are successful examples of the use of antisense mRNA in $\mathrm{Tg}$ animals for tissue-specific inhibition of target gene expression (22-24). In the present study, antisense GHS-R mRNA fused with the rat TH gene promoter (11) was used to disrupt the function of GHS-R in the hypothalamus, especially in the Arc. In fact, the expression of the antisense GHS-R mRNA was detected in almost all the TH neurons in the Arc of Tg rats, while no ectopic expression of the antisense mRNA was detected in neurons other than the TH neurons or peripheral tissues. Based on Western blot analysis and immunocytochemistry, GHS-R protein levels were decreased in the Arc of Tg rats compared with those of control rats, whereas there was no significant difference in GHS-R protein levels in the ventromedial nucleus between $\mathrm{Tg}$ and control rats. The distribution of $\mathrm{TH}$ in the Arc was not altered in $\mathrm{Tg}$ rats. These data indicate that the amount of antisense GHS-R mRNA accumulated was sufficient to suppress the synthesis of GHS-R protein in the Arc.

$\mathrm{GH}$ secretion has been shown to be regulated by two antagonistic hypothalamic peptides: GHRH, which stimulates, and somatostatin, which inhibits GH secretion from the pituitary. GHRH-containing neurons in the Arc have been proposed to be one of the central targets of ghrelin/GHS in stimulating GH secretion (10, $25,26)$. In fact, the results of the present immunocytochemical study showed that many GHRH-containing neurons in the Arc of control rats coexpressed GHS-R. As expected from the finding that the majority of the GHRH neurons in the Arc also express TH $(9,19,20)$, double-staining immunocytochemistry showed that only a few GHRH neurons in the Arc had GHS-R-like immunoreactivity in $\mathrm{Tg}$ rats. Therefore, the reduced GH response to KP-102 in Tg rats is probably due to the reduction of GHS-R in GHRH neurons in the Arc.

In our study, pulsatile GH secretion was preserved in male Tg rats, while GH secretion and plasma IGF-I levels were reduced in female $\mathrm{Tg}$ rats. Normal male rats show a regular and pronounced episodic pattern of GH secretion with extremely low basal secretion that is regulated by the cyclic rhythms of GHRH and somatostatin release (27). On the other hand, since normal female rats show a more continuous and irregular pattern of GH secretion with higher baseline levels than those of normal male rats, it appears that somatostatin output is noncyclical and rather low, and that GHRH plays a dominant role in GH secretion in female rats (27). Since somatostatin neurons do not contain $\mathrm{TH}$ (28), they should be unaffected in our Tg rats. Furthermore, the absence of GHS actions on somatostatin tone has been suggested (29). Therefore, the divergence of GH secretion between male and female $\mathrm{Tg}$ rats may be explained by the reduction of GHS-R in GHRH neurons in the Arc. It seems that in female rats, an endogenous ligand such as ghrelin plays a more important role in the regulation of $\mathrm{GH}$ secretion by stimulating GHRH neurons through GHS-R. The possibility that deletion of GHS-R in GHRH-containing neurons reduces $\mathrm{GH}$ secretion remains to be tested.

Recently, it has been reported that ghrelin and GHSs stimulate food intake in freely feeding rats $(6-8,30)$. However, the mechanism by which ghrelin/GHS promotes food intake is not fully understood. Our previous observations suggest that KP-102 and GHRH stimulate food intake via different mechanisms, and that GHRH neurons in the Arc are probably not involved in the KP102-induced stimulation of food intake (2). NPY-con-
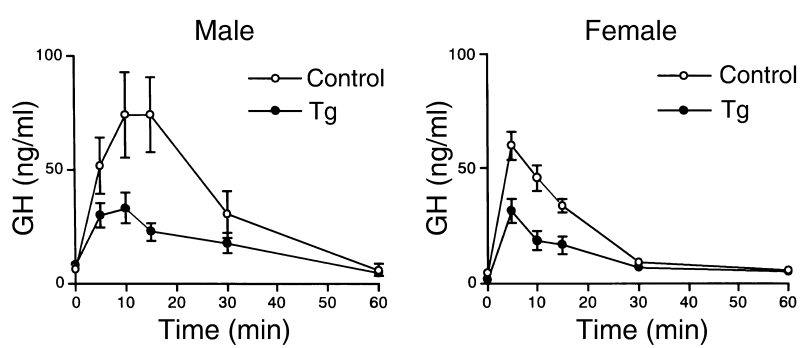

Figure 10

Effect of KP-102 $(1 \mu \mathrm{g} / \mathrm{kg})$ on GH secretion in Tg rats. The data are expressed as the mean \pm SEM of five rats. 

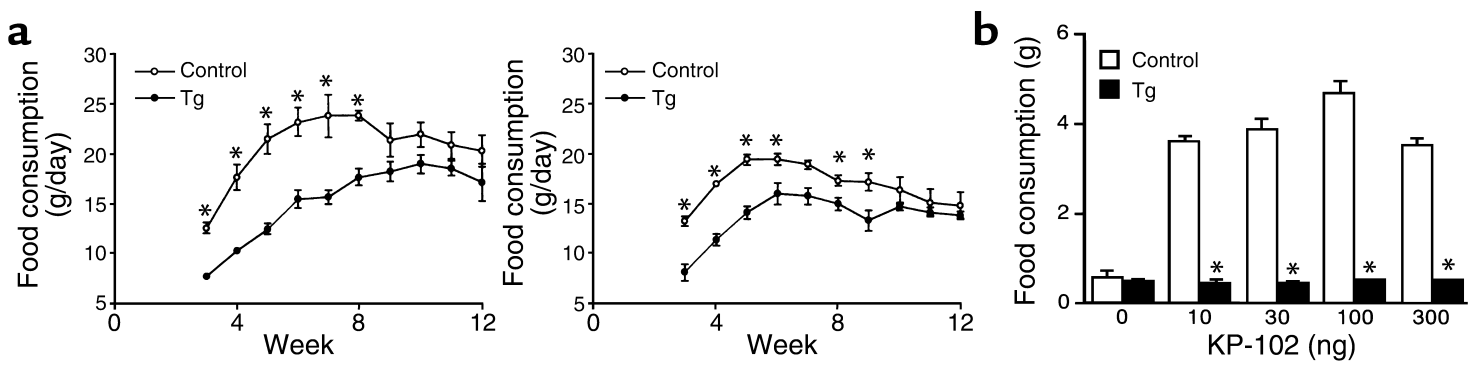

Figure 11

Food intake in Tg rats. (a) Daily food intake. ${ }^{*} P<0.05$ versus control rats. Data are expressed as the mean \pm SEM of five rats. (b) Effect of $\mathrm{KP}-102(10,30,100$, and $300 \mathrm{ng})$ on food intake. The data are expressed as the mean $\pm \mathrm{SEM}$ of ten rats. ${ }^{*} P<0.05$ versus control rats.

taining neurons participate in the stimulatory mechanism for food intake $(31,32)$. Therefore, it is assumed that NPY is involved in the stimulatory effect of ghrelin/GHS on feeding, because half of the neurons expressing c-fos mRNA after GHS injection contain NPY (25). On the other hand, a significant increase in food intake in response to ghrelin is found in NPY-deficient mice, indicating that the presence of NPY is not obligatory for stimulation of food intake (8). In NPY-deficient mice, agouti-related protein (AgRP), which also stimulates feeding, may play an important role in food intake in place of NPY, since central administration of ghrelin increases AgRP mRNA (33). In the Tg rats described here, the stimulatory effect of KP-102 on feeding behavior was abolished. GHS-R-like immunoreactivity on NPY neurons was preserved in the Arc of Tg rats, which agrees with the report that most of the NPY neurons in the Arc do not contain TH (34). Therefore, KP-102 acts on unknown but TH-positive neurons possessing GHS-R, and these neurons may be responsible for the feeding effect of ghrelin/GHS. This possibility is supported by findings that GHS induces c-fos expression in cells other than GHRH or NPY neurons $(25,35)$. It is possible that KP-102 stimulates NPY neurons indirectly. In fact, at the electron microscopic level, direct appositions between TH- and NPY-immunoreactive structures have been observed in the Arc, suggesting direct interactions between these two systems (36).

Ghrelin/GHS induces a state of positive energy balance and body weight gain by promoting food intake and reducing fat utilization $(8,30)$. Tg rats showed significantly reduced daily food intake compared with age-matched control rats. They also had significantly lower body weight and body weight/nose-tail ratios, and less adipose tissue than control rats had. These findings could be the consequence of a defect in the hypothalamic action of endogenous ghrelin, which causes body weight gain by increasing food intake and decreasing fat utilization (8). How ghrelin/GHS regulates energy balance is still unknown. GH is well-known to have metabolic actions and to be involved in lipid metabolism (37). However, it appears unlikely that the induction of a positive energy balance by ghrelin/GHS is caused by its ability to stimulate GH secretion, because ghrelin-induced adiposity is not mimicked by
GH (8). ICV administration of ghrelin suppressed serum concentrations of thyroid-stimulating hormone in rats (7). Considering that thyroid hormone increases total energy expenditure, it is possible that ghrelin/GHS regulates energy balance partly by suppressing thyroid-stimulating hormone. Further study is needed to clarify this issue.

The plasma levels of ghrelin were not significantly increased in $\mathrm{Tg}$ rats. The reduced GHS-R expression in the Arc did not seem to induce a compensatory secretion of ghrelin. The absence of a significant change in plasma prolactin levels in $\mathrm{Tg}$ rats is consistent with the intactness of TH-containing neurons in the Arc.

In summary, we have generated $\mathrm{Tg}$ rats in which the expression of GHS-R protein was selectively attenuated in the Arc. Our data suggest that the endogenous ghrelin/GHS-R system in the Arc regulates GH secretion, food intake, and adiposity. The Tg rat described here could be a useful animal model for investigating the physiological function of the ghrelin/GHS-R system in the hypothalamus.

\section{Acknowledgments}

We thank M. Ashizawa, T. Shimizu, N. Yamauchi, S. Inada, and M. Iketani for their technical assistance. This work was supported in part by grants from the Japanese Ministry of Education, Culture, Sports, Science and Technology, the Japanese Ministry of Health, Labour and Welfare, and the Foundation for Growth Science.

1. Smith, R.G., et al. 1997. Peptidomimetic regulation of growth hormone secretion. Endocr. Rev. 18:621-645.

2. Okada, K., et al. 1996. Intracerebroventricular administration of the growth hormone-releasing peptide KP-102 increases food intake in freefeeding rats. Endocrinology. 137:5155-5158.

3. Howard, A.D., et al. 1996. A receptor in pituitary and hypothalamus that functions in growth hormone release. Science. 273:974-977.

4. Guan, X.M., et al. 1997. Distribution of mRNA encoding the growth hormone secretagogue receptor in brain and peripheral tissues. Brain Res. Mol. Brain Res. 48:23-29.

5. Kojima, M., et al. 1999. Ghrelin is a growth-hormone-releasing acylated peptide from stomach. Nature. 402:656-660.

6. Nakazato, M., et al. 2001. A role for ghrelin in the central regulation of feeding. Nature. 409:194-198.

7. Wren, A.M., et al. 2000. The novel hypothalamic peptide ghrelin stimulates food intake and growth hormone secretion. Endocrinology. 141:4325-4328.

8. Tschöp, M., Smiley, D.L., and Heiman, M.L. 2000. Ghrelin induces adiposity in rodents. Nature. 407:908-913.

9. Meister, B., et al. 1986. Coexistence of tyrosine hydroxylase and growth hormone-releasing factor in a subpopulation of tubero-infundibular 
neurons of the rat. Neuroendocrinology. 42:237-247.

10. Tannenbaum, G.S., Lapointe, M., Beaudet, A., and Howard, A.D. 1998 Expression of growth hormone secretagogue-receptors by growth hormone-releasing hormone neurons in the mediobasal hypothalamus. Endocrinology. 139:4420-4423.

11. Banerjee, S.A., Roffler-Tarlov, S., Szabo, M., Frohman, L., and Chikaraishi, D.M. 1994. DNA regulatory sequences of the rat tyrosine hydroxylase gene direct correct catecholaminergic cell-type specificity of a human growth hormone reporter in the CNS of transgenic mice causing a dwarf phenotype. Brain Res. Mol. Brain Res. 24:89-106.

12. Palkovits, M. 1973. Isolated removal of hypothalamic or other brain nuclei of the rat. Brain Res. 59:449-450.

13. Shuto, Y., et al. 2001. Generation of polyclonal antiserum against the growth hormone secretagogue receptor (GHS-R): evidence that the GHS-R exists in the hypothalamus, pituitary and stomach of rats. Life Sci. 68:991-996.

14. Yamauchi, N., Shibasaki, T., Ling, N., and Demura, H. 1991. In vitro release of growth hormone-releasing factor (GRF) from the hypothalamus: somatostatin inhibits GRF release. Regul. Pept. 33:71-78.

15. Shibasaki, T., Oda, T., Imaki, T., Ling, N., and Demura, H. 1993. Injection of anti-neuropeptide $Y$ gamma-globulin into the hypothalamic paraventricular nucleus decreases food intake in rats. Brain. Res. 601:313-316.

16. Clark, R.G., Jansson, J.O., Isaksson, O., and Robinson, I.C. 1985. Intravenous growth hormone: growth responses to patterned infusions in hypophysectomized rats. J. Endocrinol. 104:53-61.

17. Shibasaki, T., et al. 1998. The growth hormone secretagogue KP-102induced stimulation of food intake is modified by fasting, restraint stress, and somatostatin in rats. Neurosci. Lett. 255:9-12.

18. Kuriyama, H., Hotta, M., Wakabayashi, I., and Shibasaki, T. 2000. A 6 day intracerebroventricular infusion of the growth hormone-releasing peptide KP-102 stimulates food intake in both non-stressed and intermittently-stressed rats. Neurosci. Lett. 282:109-112.

19. Niimi, M., Takahara, J., Sato, M., and Kawanishi, K. 1992. Identification of dopamine and growth hormone-releasing factor-containing neurons projecting to the median eminence of the rat by combined retrograde tracing and immunohistochemistry. Neuroendocrinology. 55:92-96.

20. Zoli, M., Agnati, L.F., Tinner, B., Steinbusch, H.W., and Fuxe, K. 1993. Distribution of dopamine-immunoreactive neurons and their relationships to transmitter and hypothalamic hormone-immunoreactive neuronal systems in the rat mediobasal hypothalamus. A morphometric and microdensitometric analysis. J. Chem. Neuroanat. 6:293-310.

21. Merriam, G.R., and Wachter, K.W. 1982. Algorithms for the study of episodic hormone secretion in stalk-sectioned rats. Am. J. Physiol. 243:E310-E318.

22. Moxham, C.M., Hod, Y., and Malbon, C.C. 1993. Induction of G alpha i2-specific antisense RNA in vivo inhibits neonatal growth. Science. 260:991-995.
23. Pepin, M.-C., Pothier, F., and Barden, N. 1992. Impaired type II glucocorticoid-receptor function in mice bearing antisense RNA transgene. Nature. 355:725-728.

24. Manshouri, T., et al. 1997. Downregulation of RAR $\alpha$ in mice by antisense transgene leads to a compensatory increase in RAR $\beta$ and RAR $\gamma$ and development of lymphoma. Blood. 89:2507-2515.

25. Dickson, S.L., and Luckman, S.M. 1997. Induction of c-fos messenger ribonucleic acid in neuropeptide $Y$ and growth hormone (GH)-releasing factor neurons in the rat arcuate nucleus following systemic injection of the GH secretagogue, GH-releasing peptide-6. Endocrinology. 138:771-777.

26. Kamegai, J., et al. 1998. Growth hormone-dependent regulation of pituitary GH secretagogue receptor (GHS-R) mRNA levels in the spontaneous dwarf rat. Neuroendocrinology. 68:312-318.

27. Robinson, I.C.A.F. 1991. The growth hormone secretory pattern: a response to neuroendocrine signals. Acta Paediatr. Scand. Suppl. 372:70-78.

28. Everitt, B.J., et al. 1986. The hypothalamic arcuate nucleus-median eminence complex: immunohistochemistry of transmitters, peptides and DARPP-32 with special reference to coexistence in dopamine neurons. Brain Res. 396:97-155.

29. Tannenbaum, G.S., and Bowers, C.Y. 2001. Interactions of growth hormone secretagogues and growth hormone-releasing hormone/somatostatin. Endocrine. 14:21-27.

30. Asakawa, A., et al. 2001. Ghrelin is an appetite-stimulatory signal from stomach with structural resemblance to motilin. Gastroenterology. 120:337-345

31. Kalra, S.P., and Horvath, T.L. 1998. Neuroendocrine interactions between galanin, opioids, and neuropeptide $\mathrm{Y}$ in the control of reproduction and appetite. Ann. NY Acad. Sci. 863:236-240.

32. Gehlert, D.R. 1999. Role of hypothalamic neuropeptide $\mathrm{Y}$ in feeding and obesity. Neuropeptides. 33:329-338.

33. Kamegai, J., et al. 2000. Central effect of ghrelin, an endogenous growth hormone secretagogue, on hypothalamic peptide gene expression. Endocrinology. 141:4797-4800.

34. Everitt, B.J., et al. 1984. Differential co-existence of neuropeptide Y (NPY)-like immunoreactivity with catecholamines in the central nervous system of the rat. Neuroscience. 11:443-462.

35. Kamegai, J., Hasegawa, O., Minami, S., Sugihara, H., and Wakabayashi, I. 1996. The growth hormone-releasing peptide KP-102 induces c-fos expression in the arcuate nucleus. Brain Res. Mol. Brain Res. 39:153-159.

36. Guy, J., and Pelletier, G. 1988. Neuronal interactions between neuropeptide Y (NPY) and catecholaminergic systems in the rat arcuate nucleus as shown by dual immunocytochemistry. Peptides. 9:567-570.

37. Thorner, M.O., et al. 1998. Growth hormone actions. In Williams textbook of endocrinology. 9th edition. J.D. Wilson, D.W. Foster, H.M. Kronenberg, and P.R. Larsen, editors. W.B. Saunders Co. Philadelphia, Pennsylvania, USA. $260-263$ 